\title{
Bulk Utilization of Red Mud in Geopolymer Based Products
}

\author{
Abhisek Mohapatra ${ }^{1 *}$, Prasanta Bose ${ }^{2}$, Sagar S Pandit², Sanjay Kumar ${ }^{1}$, T.C. Alex ${ }^{1}$ \\ 1. CSIR-National Metallurgical Laboratory, Jamshedpur, India \\ 2. Hindalco, Muri, Ranchi, India \\ Email: abhisek95567@gmail.com (Corresponding author)
}

Received: 2 November 2020; Accepted: 26 November 2020; Available online: 25 December 2020

\begin{abstract}
Red Mud is the solid residue generated from Alumina refinery during the process of bauxite ore processing through Bayer's process. Typical generation of red mud is 1.5 tons of red mud per ton of alumina produced. The disposal and storage of red mud has been a concern for the alumina industry since its inception, more than a hundred years ago. With the increase in alumina production, the magnitude of the problem is getting multiplied. Its alkaline nature $\left(\mathrm{Na}_{2} \mathrm{O} \sim 3-7 \%\right)$ and fine size make red mud unsuitable for many applications; a limited utilization is reported in cement industries as one of the raw mix components for cement. The present work deals with the utilization of red mud in geopolymer based paving blocks. Alumina, silica and alkali are the essential items required for geopolymer preparation. Having all these in red mud, the current study attempted to use the same in geopolymer based products. The focus has been on bulk utilization of red mud; target strength of $20 \mathrm{MPa}$ after 28 days of curing (M20 grade) has been the goal as this strength is sufficient for many applications. The study focused on optimizing the red mud content, alkali concentration, fly ash content, etc. The samples are tested for its compressive strength and leachability. The study reveals that significant amount of red mud incorporation is possible with products conforming to USEPA 1311 norms.
\end{abstract}

Keywords: Red mud; Fly ash; Geopolymer; Compressive strength; TCLP.

\section{Introduction}

Red mud is the by-product of the Bayer process of alumina production from bauxite ore. Over 95\% of the alumina produced all over the world is derived from bauxite using the Bayer process of alumina production [1] and the rest is either produced by the sintering process or a combination of both Bayer and sintering processes [2].In the Bayer process of alumina production, bauxite ore is treated with concentrated caustic solution at an elevated temperature and pressure; the alumina from the Al-hydroxide phases of bauxite ore are brought in to the solution, leaving the undissolved components in the residue- the red mud. This waste, red mud, derives its red color from its high content in iron (III) oxide about $20-40 \%$ by mass of the red mud depending on the bauxite origin [1, 3, 4]; it has high alkalinity (pH value 10 to 13). About 1 to 1.5 ton of red mud per 1 ton of alumina [5]. Having practically no use, alumina plants generally dump the red mud in red mud ponds. Unscientific disposal of red mud leads to seepage of heavy metals and radio nuclides to the surrounding. Alkaline airborne dust emissions are also possible from dried red mud. Need of large land area for disposal is also a concern of the alumina industry. Thus the red mud having a hazardous and toxic nature causes damage to the ecology and environmental, and can be disastrous if the storage dams fail [6]; the spillage of 700,000 $\mathrm{m}^{3}$ of red mud slurry having high $\mathrm{pH}$ value of about 12 in Ajka, Hungary has caused of the loss of 10 humans and burning of hundreds people besides devastation of more than 40 square $\mathrm{km}[7,8]$.

The problem of red mud has been existing since its inception in 1880 by Karl Josef Bayer; increase together with no demand has caused exponential pile up of the red mud inventory - 1 billion ton in 1985, doubled in 15 years. Such large accumulation is a great concern for the alumina industry. Though efforts have been made by various stake holders for a solution, an acceptable one is yet to be developed. Metal extraction (iron, titanium), wastewater treatment, use in cement manufacturing etc. have been tried; but high alkalinity, fine nature; unacceptable levels of alumina are a problem in most of the areas. Attempt has been made by previous researchers to utilize the red mud in various civil engineering construction works such as subgrade, mine tailings and so on based on its unique chemical, physical and mineralogical properties [9-15]. It is better to have a bulk application wherein its alkaline nature, silica and alumina contents are not a problem. For geopolymers, these radicals (silica, alumina and $\mathrm{Na}_{2} \mathrm{O}$ ) are not an issue at all, but they are essential ingredients, as described below.

Geopolymers are formed when fine alumino-silicate (natural or synthetic) material reacts alkali solution of suitable concentration, typically at room temperature. The reaction sequence involves dissolution of alumina and 
silica, reorientation of $\mathrm{SiO}_{4}{ }^{-}$and $\mathrm{AlO}_{4}{ }^{-}$tetrahedral units to form monomers, cross linking of these to form a wide spectrum of structures [16-19]. The polysialate $\mathrm{Si}-\mathrm{O}-\mathrm{Al}-\mathrm{O}$ bonds of geopolymers can be as described by the formula:

$$
\mathrm{M}_{\mathrm{n}}\left[-\left(\mathrm{Si}-\mathrm{O}_{2}\right)_{\mathrm{z}}-\mathrm{Al}-\mathrm{O}\right]_{\mathrm{n}} \cdot \mathrm{wH}_{2} \mathrm{O}
$$

Where $\mathrm{n}$ is the degree of polymerization, $\mathrm{z}$ is 1,2 or 3 and $\mathrm{M}$ is an alkali cation, such as potassium or sodium. Fly is a typical low cost aluminosilicate material used in geopolymer preparation. Since red mud is having alumina and soda content, it supplements for geopolymerization if red mud is used along with fly ash [20].

\section{Materials and methods}

\subsection{Materials}

Red mud used in these studies is from Hindalco refinery at Muri, Ranchi (Jharkhand); red mud has been obtained in dry powder form. Fly ash also has been obtained from the captive power plant of Hindalco refinery at Muri. All other materials, such as Ordinary Portland cement (OPC), sand, reagent etc used in the study have been of commercial grade.

\subsection{Methods}

The main raw materials used in the study viz. fly ash and red mud are characterized by chemical analysis, particle size distribution, and mineral phase analysis. Conventional wet chemical analysis method has been adopted for analyzing the chemical composition. Particle size distributions of the samples are determined using a laser diffraction based equipment (Mastersizer, Malvern, UK). Mineral phases present in the samples are deduced from the X-ray diffraction patterns from a Bruker D50 (Germany) using $\mathrm{Cu} \mathrm{K}_{\alpha}$ radiation.

Geopolymer samples are prepared from fly ash and red mud as detailed here. Fly ash-redmud-OPC, fine aggregate and coarse aggregate in a ratio of 2:3:5 are mixed in a concrete mixer. The mix design used has targeted an M20 grade concrete (20 MPa after 28 days of curing). Use of OPC has been kept constant at 5\% and fly ash is replaced by red mud in proportion varying from 0 to $40 \%$. This dry mixed material is then mixed with the binder solution, a mix of $6 \mathrm{M}$ of $\mathrm{NaOH}$ solution and $\mathrm{Na}_{2} \mathrm{SiO}_{3}$ solution in $1: 1$ ratio by volume. The amount of binder solution varied from $11-13 \%$ by weight. The mix is then cast in $70 \times 70 \times 70 \mathrm{~mm}$ steel molds and vibrated for $2 \mathrm{~min}$ in a vibration machine. The cast sample was left in the mold for $24 \mathrm{~h}$ in a humidity chamber and thereafter demolded. The demolded sample kept in humidity chamber has been tested for its compressive strength after 1, 7 and 28 days of curing.

\section{Results and discussion}

\subsection{Characterization of raw materials}

The physical properties of the materials (red mud and fly ash) used in the study are presented in Table 1. It can be seen that the colors are typical of the materials. Slightly higher density of red mud is due to presence of iron minerals in larger quantities than that in fly ash, as can be seen from the chemical analysis and the mineral phases revealed in the XRD pattern. Specific surface area measured by BET method (ASAP 2020, Micromertics, US) shows that the surface area of $2.68 \mathrm{~m}^{2} / \mathrm{g}$ for the fly ash, and is typical; on the other hand, the specific surface area of red mud, $\sim 20 \mathrm{~m}^{2} / \mathrm{g}$, is significantly high. This indicates that the material make-up of red mud is porous in nature. This can be expected as red mud is a byproduct obtained after dissolving/digesting the alumina content from the bauxite ore.

Table 1. Physical properties of the material used

\begin{tabular}{lll}
\hline Property & Red Mud & Fly Ash \\
\hline Color & Reddish & Brownish \\
Density, g/cc & 3.03 & 2.46 \\
Surface area, $\mathrm{m}^{2} / \mathrm{g}$ & 20.46 & 2.68 \\
\hline
\end{tabular}

Chemical analysis of the red mud and fly ash used in the study are presented in Table 2. It shows that the fly ash is of Class F category (having $\mathrm{CaO}$ content less than 14\%). The predominant radicals in fly ash are silica and alumina, and are in a suitable proportion for geopolymerization process. For the red mud, alumina and silica are much lower compared to that of fly ash, and is in a reverse ratio to that observed for fly ash. Thus, the active components, alumina and silica, are too low (in red mud) to serve as a raw material for geopolymerization on its own. However, the $\mathrm{Na}_{2} \mathrm{O}$ content, $\sim 5 \%$, of red mud is advantageous as far as the geopolymer process is contained. Available silica, alumina and $\mathrm{Na}_{2} \mathrm{O}$ will be used up in the process. 
Table 2. Chemical analysisis (\%) of fly ash and red mud used

\begin{tabular}{cll}
\hline Radical & Red mud & Fly ash \\
\hline $\mathrm{SiO}_{2}$ & 7.37 & 60.20 \\
$\mathrm{Al}_{2} \mathrm{O}_{3}$ & 15.10 & 29.12 \\
$\mathrm{CaO}$ & 1.86 & 1.12 \\
$\mathrm{P}_{2} \mathrm{O}_{5}$ & 0.30 & 0.55 \\
$\mathrm{Fe}_{2} \mathrm{O}_{3}$ & 38.0 & 4.36 \\
$\mathrm{~V}_{2} \mathrm{O}_{5}$ & $\mathrm{NA}$ & 0.04 \\
$\mathrm{TiO}_{2}$ & 13.83 & 1.93 \\
$\mathrm{Na}_{2} \mathrm{O}$ & 5.50 & $\mathrm{NF}$ \\
$\mathrm{K} \mathrm{O}$ & $\mathrm{NA}$ & $\mathrm{NA}$ \\
$\mathrm{MgO}$ & $\mathrm{NA}$ & $\mathrm{NA}$ \\
$\mathrm{LOI}$ & 10.54 & 0.12 \\
\hline
\end{tabular}

NA- Not analysed, NF-Not found

Particle size distribution (PSD) of both the fly ash and the red mud are presented in Fig. 1. It can be seen that the PSD of red mud is a multimodal curve with the most prominent mode is observed at the finer size, indicating the fine nature of the red mud. Though the PSD of fly ash also multimodal in nature, it is coarser than that of the red mud. Characteristic diameters derived from the cumulative undersize curves are presented in Table 3.
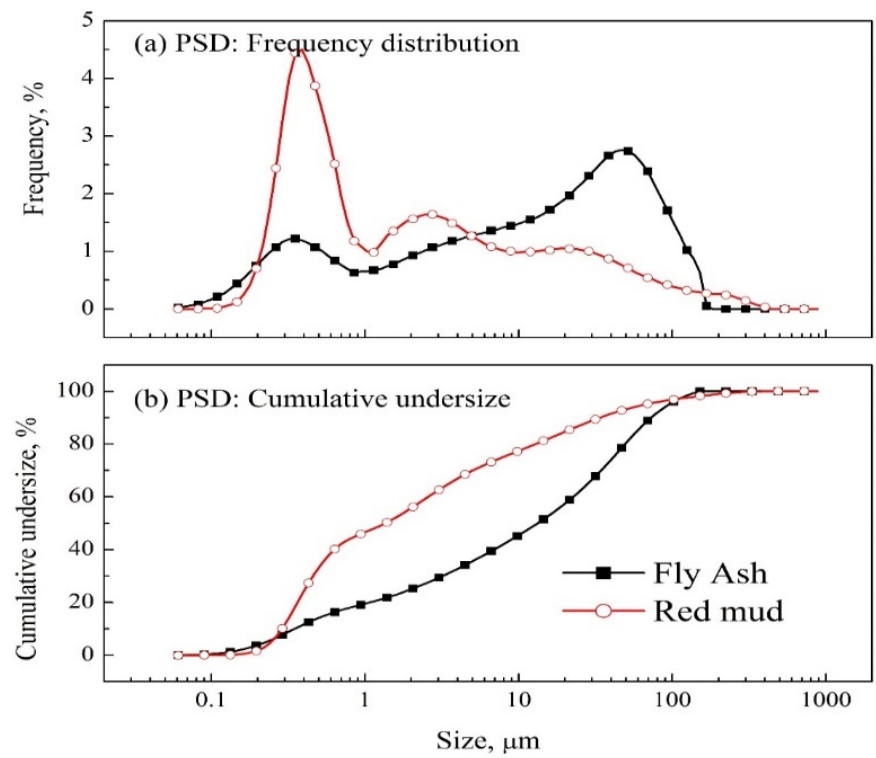

Fig. 1. Particle size distribution of fly ash and red mud used (a) Frequency distribution, (b) Cumulative undersize curve (Not all data points are shown in the plot)

Table 3. Characteristic diameters and specific surface area deduced from PSD

\begin{tabular}{lll}
\hline Chracteristic diameter & Fly ash & Red mud \\
\hline $\mathrm{D}_{10}, \mu \mathrm{m}$ & 0.32 & 0.26 \\
$\mathrm{D}_{50}, \mu \mathrm{m}$ & 12.08 & 1.23 \\
$\mathrm{D}_{90}, \mu \mathrm{m}$ & 66.03 & 30.69 \\
$\mathrm{Sp} \mathrm{SAA}, \mathrm{cm}^{2} / \mathrm{g}$ & 2.64 & 4.60 \\
\hline
\end{tabular}

NA- not analysed

As mentioned earlier, the mineral phases in the red mud and Fly Ash are analyzed using the X-ray diffraction pattern of the red mud obtained using a Bruker D80 X-ray diffractometer with $\mathrm{Cu} \mathrm{K \alpha}$ as the radiation. The X-ray diffraction pattern obtained is presented in Fig. 2. The pattern obtained is analyzed using the software available with the diffractometer for the possible phases. Phases present in the sample are marked in the pattern (Fig 2). Prominence of hematite and goethite observed in the pattern for red mud is responsible for the significant amount of Fe indicated in the chemical analysis (Table 2). Alumina in the chemical analysis stems from the sodalite, gibbsite, and to a certain extent from the goethite (embedded in the lattice). Titania is present in the mineral forms rutile and anatase. Though some of the peaks match with that of lime, chemical analysis precludes its presence. 

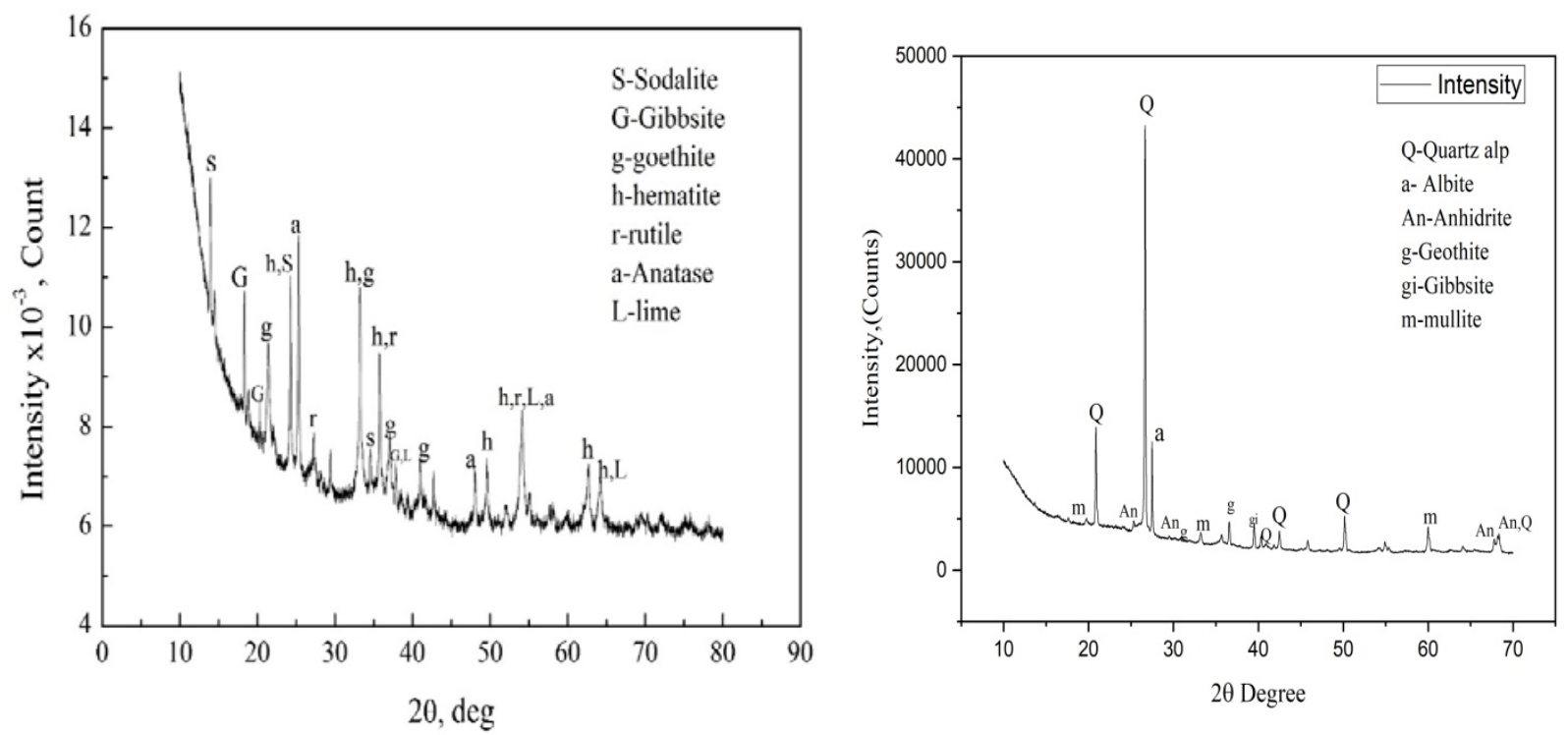

Fig 2. X-ray diffraction pattern of the red mud and Fly Ash used

\subsection{Product evaluation}

As described earlier, a mix design of grade M20 has been used. The composition of the charge mix used is: Fly ash+ Red mud: Sand: Aggregates $=2: 3: 5$ by weight; binder used is a 1:1 mix of $6 \mathrm{M} \mathrm{NaOH}+$ sodium silicate solution (commercial grade). As per the mix design, control mix prepared is cast in $70 \times 70 \times 70 \mathrm{~mm}$ mold (Fig. 3). The fly ash in the mix has been replaced with red mud in varying amounts to see the effect of red mud on the quality of the samples in terms of its compressive strength and leachability. In these samples, $5 \%$ OPC has also been added to enhance its physical properties.

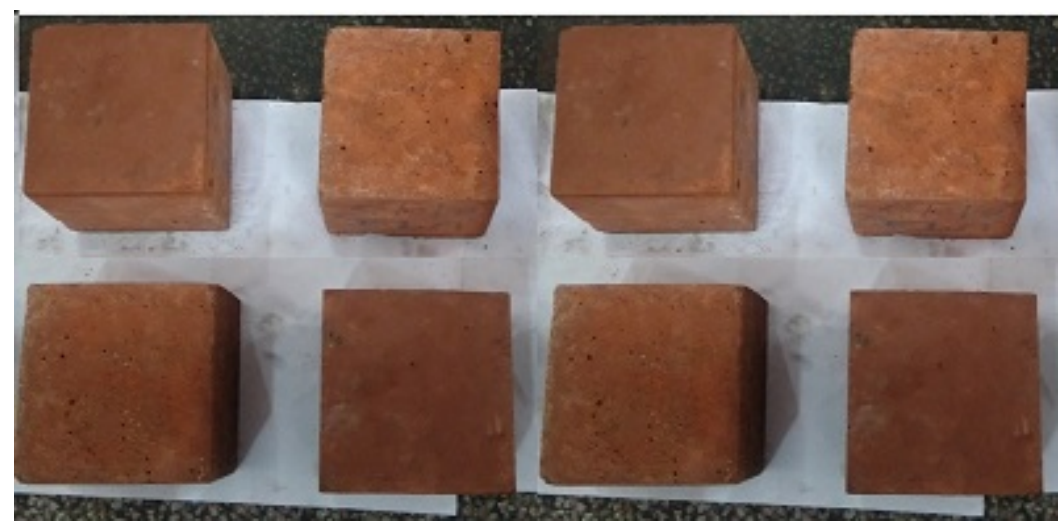

Fig 3. Cubic samples (70x70x70 mm) prepared in this study

\subsection{Mechanical properties of geopolymer product}

The samples prepared with varying amounts of red mud have been cured for different periods in curing chambers. Compressive strength of the samples has been tested after a curing of 1day, 7 day and 28 day. For testing the compressive strengths test an automated compression testing machine is used. Visually defect free samples have been tested for compressive strength determination. Each test has been done three times and the average has been reported. The compressive strength of the test samples obtained for varying red mud contents after 28 days are presented in Fig. 4; the compressive strength data for 1 day and 7day also have been included in the figure for comparison.

Compressive strength values of test samples with fly ash alone (no red mud also) are also included in the figure for comparison. As can be seen from the figure, the compressive strength of the samples decreases with increase in the red mud content of the sample. The trend is same irrespective of the curing time (1, 3, 7 and 28 day); for clarity, the compressive strength variation at three-day curing is not presented. The average decrease in one-day strength is around $0.4 \mathrm{MPa}$ for every one percent increase of red mud. The samples up to $5 \%$ red mud has attained the target strength of $20 \mathrm{MPa}$ in seven days itself. At this aging, the decrease in compressive strength has been slightly less with increase in red mud ( 0.34 MPa per every $1 \%$ increase in red mud). The target strength for M20 
(20 MPa after curing for 28 day) is achieved for many compositions having red mud up to $28 \%$. The rate of decrease of compressive strength with increase in red mud content has further decreased (0.28 MPa for every $1 \%$ increase in red mud) after curing for 28 day. Reasons for the decrease in strength are many such as decrease in the active components, increase in inert materials etc. Detailed study is in progress and will be dealt in a separate paper. The extent of incorporation can be enhanced with minor increase in the OPC content; studies have shown that up to $40 \%$ of red mud is tolerable.

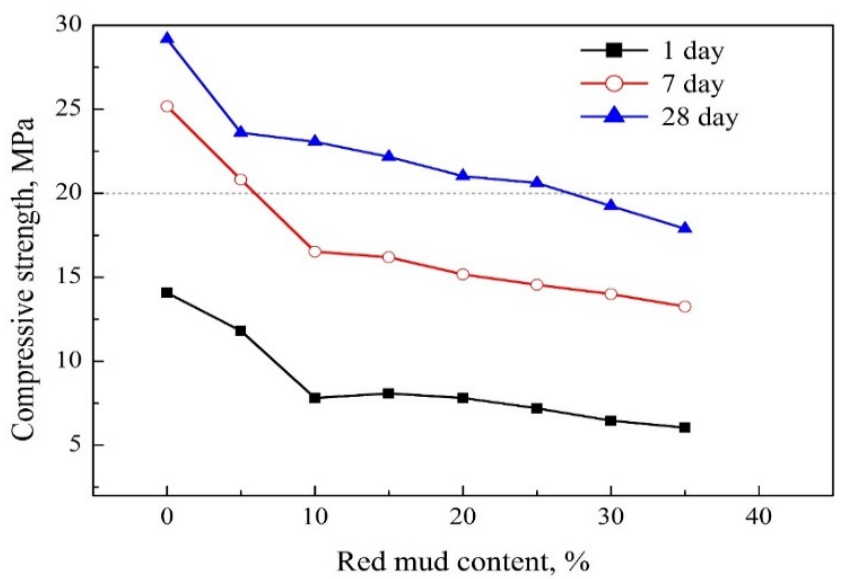

Fig 4. Compressive strength values at different aging times - variation

\subsection{Leaching Behavior of geopolymer products}

Leaching of heavy metals from the products is studied using the toxicity content by leaching protocol (TCLP) recommended by US environmental protection agency (USEPA 1311). For this purpose, the geopolymer samples are prepared with fly ash and red mud only so as to get the correct picture; separation of geopolymer matrix is difficult from samples prepared for compression testing wherein the matrix is intricately mixed with the aggregates. Results obtained in the TCLP tests for a geopolymer having fly ash and red mud in the ratio of 60:40 (by weight) are presented in Table 4. It can be seen that the leachability as per TCLP protocol for all elements is very much below the USEPA limit. Further, it is seen that the amount leached generally decreases with the geopolymerization, showing the acceptability of the product as per USEPA norms. Similar approach is seen in another literature [21] for another red mud sample from Eastern Ghats bauxite.

Table 4. TCLP results of geopolymer product after $28 \mathrm{~d}$ curing

\begin{tabular}{lllll}
\hline & & \multicolumn{3}{c}{ Analysis in ppm } \\
Radical & Fly ash & Red mud & Geopolymer & USEPA limits \\
\hline $\mathrm{Ag}$ & 0.03 & 0.06 & BDL & 5.0 \\
$\mathrm{Hg}$ & $\mathrm{BDL}$ & BDL & BDL & 0.2 \\
$\mathrm{~Pb}$ & 0.03 & 0.25 & BDL & 5.0 \\
$\mathrm{Se}$ & BDL & BDL & BDL & 1.0 \\
$\mathrm{Cr}$ & 0.03 & 0.27 & 0.14 & 5.0 \\
$\mathrm{Cd}$ & BDL & BDL & 0.01 & 1.0 \\
$\mathrm{Ba}$ & 0.90 & 0.22 & 0.85 & 100.0 \\
$\mathrm{As}$ & BDL & BDL & BDL & 5.0 \\
\hline
\end{tabular}

BDL-Below Defection Level

\section{Conclusions}

This paper focuses on bulk utilization of red mud in geopolymer based paving blocks and concrete. Main focus has been on bulk utilization of red mud. the strength targeted has been $20 \mathrm{MPa}$ after 28 days of curing (M20 grade); this strength is sufficient for common pavements. Physical characterization indicates that the red mud is porous as its having high specific surface area. The chemical analysis data of red mud shows high content of iron oxide. Significant amount of $\mathrm{Al}_{2} \mathrm{O}_{3}$ and $\mathrm{Na}_{2} \mathrm{O}$ are beneficial for the geopolymerization; $\mathrm{Na}_{2} \mathrm{O}$ content of red mud, a hindrance to its use in many applications, is gainfully utilized in geopolymers. The leachability studies data of red mud shows that it is environmentally safe as the release of toxic trace elements level is below the limit set by the USEPA. The salient points of this study are summarized as:

1) Red mud incorporation reduces the compressive strength of geopolymer based pavers. 
2) M20 grade is possible with red mud up to $30 \%$ by weight along with $5 \%$ OPC.

3) Further enhanced red mud incorporation is possible with slight increase in OPC content.

4) TCLP confirms that the geopolymer product conforms to USEPA 1311 norms and, hence, environmentally safe.

5) Geopolymerization opens up a way for bulk utilization of red mud.

\section{Acknowledgement}

Authors are thankful to The Director of CSIR-NML, Jamshedpur for his valuable support. Authors acknowledges DST (DST/TDT/WMT/2017/055-G) and HINDALCO for their support for this work.

\section{References}

[1] International Aluminium Institute. Bauxite Residue Management: Best Practice. 2015.

[2] Dentoni, V., Grosso, B., Massacci, G. Environmental sustainability of the alumina industry in Western Europe. Sustainability $2014 ;(6):$ 9477-9493.

[3] Rai, S., Wasewar, K.L., Mukhopadhyay, J., Yoo, C.K., Uslu, H. Neutralization and utilization of red mud for its better waste management. Arch. Environ. Science. 2012; 6:13-33.

[4] Tsakiridis, P.E., Agatzini-Leonardou, S., Oustadakis, P. Red mud addition in the raw meal for the production of Portland cement clinker. Journal of Hazard. Mater. 2004;116:103-110.

[5] Zhang R, Zheng S, Ma S, Zhang Y. Recovery of alumina and alkali in Bayer red mud by the formation of andradite-grossular hydrogarnet in hydrothermal process. Journal of Hazard. Mater. 2011;189 (3): $827-835$.

[6] Liu, Y., Lin, C., Wu, Y. Characterization of red mud derived from a combined Bayer process and bauxite calcination method. J. Hazard. Mater. 2007; 146 (1): 255-261.

[7] Ruyters S, Mertens J, Vassilieva E, Dehandschutter B, Poffijn A, Smolders E. The red mud accident in Ajka (Hungary): plant toxicity and trace metal bioavailability in red mud contaminated soil. Environ Sci Technology .2011;45:1616-1622.

[8] Gelencsér A, Kováts N, Turóczi B, Rostási Á, Hoffer A, et al. The red mud accident in Ajka (Hungary): characterization and potential health effects of fugitive dust. Environ Sci Technol. 2011; 45:1608-1615.

[9] Mukiza E, Zhang L, Liu X, Zhang N. Utilization of red mud in road base and subgrade materials: a review. Res Conserv Recycl. 2019; 141:187-199.

[10] Newson T, Dyer T, Adam C, Sharp S. Effect of structure on the geotechnical properties of bauxite residue. J Geotech Geoenviron Eng. 2006; 132(2):143-151.

[11] Nikraz HR, Bodley AJ, Cooling DJ, Kong PYL, Soomro. Comparison of physical properties between treated and untreated bauxite residue mud. J Mater Civ Eng. 2007; 19(1):2-9

[12] Rout SK, Sahoo T, Das SK. Design of tailing dam using red mud. Central Eur J Eng. 2013; 3(2):316-328.

[13] Smičiklas I, Smiljanić S, Perić-Grujić A, Šljivić-Ivanović M, Mitrić M, Antonović D. Effect of acid treatment on red mud properties with implications on Ni (II) sorption and stability. Chem Eng J. 2014; 242:27-35.

[14] Zhong L, Zhang Y, Zhang Y. Extraction of alumina and sodium oxide from red mud by a mild hydro-chemical process. J Hazard Mater. 2009; 172(2-3):1629-1634

[15] Jha Arvind kumar, Kumar Dhanraj, P.V. Sivapullaiah Influence of Fly Ash on Geotechnical Behaviour of Red Mud: A Micro-mechanistic Study. Geotech Geol Eng. 2020

[16] Glukhovsky VD. Soil silicates. Gosstroyizdat, Kiev, Russia. 1959.

[17] Duxson P, Fernandez-Jimenez A, Provis J, Lukey G, Palomo A, van Deventer J. Geopolymer technology: The current state of the art. Journal. Mater Sci. 2007; 42(9): 2917-2933.

[18] van Jaarsveld JGS, van Deventer JS, Lukey GC. The effect of composition and temperature on the properties of fly ash- and kaolinite- based geopolymers. Chem. Engg. Journal. 2002; 89(1-3): 63-73.

[19] Fernandez-Jimenez, A., Palomo, A. Characterisation of fly ashes. Potential reactivity as alkaline cements. Fuel. 2003; 82(18): 2259-2265.

[20] Luping Tang. Study of the possibilities of using Red Mud as an additive in concrete and grout mortar. International Journal for Research and Organization. 2014;10:33-59.

[21] Kumar A, Kumar S. Development of paving blocks from synergistic use of red mud and fly ash using geopolymerization. Constr. Build.Mater. 2013; 38: 865-871.

(C) 2020 by the author(s). This work is licensed under a Creative Commons Attribution 4.0 International License (http://creativecommons.org/licenses/by/4.0/). Authors retain copyright of their work, with first publication rights granted to Tech Reviews Ltd. 